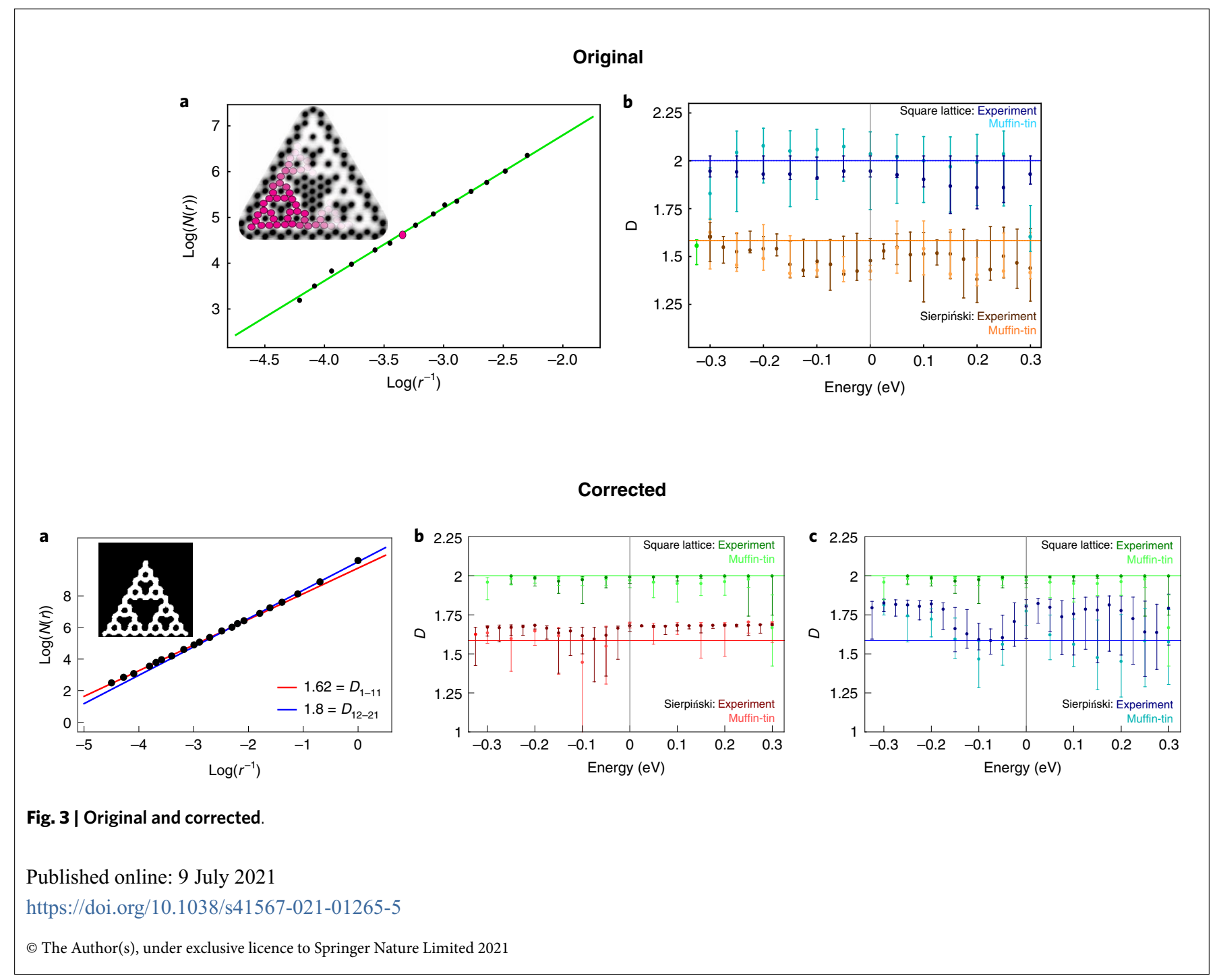

\title{
Author Correction: Maximum information states for coherent scattering measurements
}

Dorian Bouchet (D), Stefan Rotter (1) and Allard P. Mosk (iD)

Correction to: Nature Physics https://doi.org/10.1038/s41567-020-01137-4; published online 21 January 2021.

In the Supplementary Information file originally published with this Letter, owing to a mistake in the derivative used to calculate equation (S11), the original version of this equation in Supplementary Information section S1.2 was incorrect. However, this did not affect the final result of the Fisher information given by equation (S18), which was stated correctly. Equation (S11) and all subsequent expressions affected by the mistake have now been corrected. The amended Supplementary Information file has now been uploaded to the Letter.

Published online: 22 June 2021

https://doi.org/10.1038/s41567-021-01304-1

(c) The Author(s), under exclusive licence to Springer Nature Limited 2021 